\title{
Effectuation e a influência das redes sociais em internacionalização de startups em aceleradoras
}

\author{
Carolaine Fabricia Bonk Sarmento ${ }^{1}$, \\ Carlos Augusto Septimio de Carvalho e Luis Antonio da Rocha Dib \\ Universidade Federal do Rio de Janeiro - UFRJ, Rio de Janeiro, RJ, Brasil.
}

\section{DETALHES DO ARTIGO}

\section{Histórico do artigo:}

Recebido em 29 de junho de 2015

Aceito em 3 de fevereiro de 2016

Disponível online em 30 de abril de 2016

Sistema de Revisão "Double Blind Review"

Editor científico:

Eduardo Eugênio Spers

\section{Palavras-chaves:}

Empreendedorismo internacional

Redes sociais

Effectuation

Aceleradoras

Indústria musical

\begin{abstract}
RESUMO
Aceleradoras recentemente se tornaram uma alternativa mais atuante do que as incubadoras como um mecanismo de apoio e desenvolvimento de startups de base tecnológica, inclusive em sua internacionalização. Ao mesmo tempo, redes sociais possibilitam e aumentam a velocidade do processo de internacionalização de pequenas firmas por meio da obtenção de recursos de terceiros e de conhecimento de mercado. Neste contexto, o objetivo desta pesquisa foi a busca de uma maior compreensão sobre como as aceleradoras agilizam o processo de internacionalização das startups nelas incubadas. Foi realizado um estudo de caso único em profundidade de uma startup de internet. A análise do processo de internacionalização da empresa teve como base teórica a abordagem do empreendedorismo internacional e a teoria de effectuation. Os resultados indicaram que a startup se beneficiou de recursos e conhecimentos obtidos por meio da aceleradora, os quais seriam comumente obtidos por meio de uma rede social. Além disso, a aceleradora, substituindo a rede social informal de maneira formal e estruturada, foi capaz de aumentar a velocidade de internacionalização da firma. A principal contribuição deste artigo é a de iluminar mais detalhadamente a conexão entre os princípios teóricos da effectuation e o uso de redes sociais na internacionacionalização de pequenas firmas.
\end{abstract}

(C) 2016 Internext | ESPM. Todos os direitos reservados!

\section{Introdução}

Em um ambiente econômico globalizado, a rápida internacionalização da pequena empresa nascente (startup) inovadora é considerada fundamental para o desenvolvimento do país (Sebrae, 2006). Por exemplo, a Apex-Brasil tem contribuído para o aumento na velocidade de internacionalização das startups brasileiras por meio de estudos de mercado e apoio na participação em eventos e feiras internacionais (Apex-Brasil, 2015). Ao mesmo tempo, o reconhecimento da alta taxa de mortalidade da pequena empresa, que pode chegar a $60 \%$ nos primeiros quatro anos de vida (Sebrae, 2004), levou à criação de entidades de apoio ao crescimento das startups tais como incubadoras e aceleradoras (Anprotec, 2012). O crescimento e desenvolvimento das aceleradoras tem sido também apoiadas pelo governo federal por meio de programas estatais de incentivo tecnológico, como o programa START-UP BRASIL (Brasil, 2014), e até mesmo multinacionais como a Microsoft criaram suas próprias aceleradoras em busca de mais oportunidades de inovação (Microsoft Venture, 2014). Em termos de número de aceleradoras, de 2011 a 2014 foram criadas quase 40 aceleradoras no Brasil (Aguilhar, 2014), e no mundo todo as estimativas vão de 300 a 2.000 aceleradoras operantes em todos os continentes (Cohen e Hochberg, 2014).

Ao mesmo tempo, a literatura de internacionalização de empresas já possui um extenso corpo de estudos sobre o empreendedorismo internacional (Jones, Coviello e Tang, 2011), o qual se dedica especialmente às pequenas firmas de internacionalização rápida, 
também chamadas de international new ventures ou born globals (Oviatt e Mcdougall, 1994). Dentro desta literatura, a rede social é reconhecida como um fator importante para a internacionalização rápida das born globals, pois atua como mecanismo que influencia este processo (Oviatt e Mcdougall, 2005), especialmente na obtenção de recursos (Coviello e Cox, 2006) e de conhecimento sobre mercados internacionais (Bell et al., 2003). Adicionalmente, a teoria de efetivação (effectuation) apresenta princípios da heurística cognitiva usada por empreendedores (Sarasvathy, 2008) em condições de extrema incerteza (o que caracteriza quase sempre a entrada em mercados internacionais) e de recursos escassos (típicos de pequenas empresas nascentes). Pelo fato de estas condições serem bastante comuns em processos de internacionalização de pequenas empresas, a teoria de efetivação pode ajudar na compreensão do seu processo de internacionalização por meio de redes (Sarasvathy et al., 2014).

Devido ao fato de as aceleradoras serem um fenômeno ainda recente e poucas startups terem já se graduado, existe uma grande escassez de estudos (principalmente empíricos), sobre aceleradoras e aceleradas (Cohen e Hochberg, 2014). Assim, buscouse na literatura estudos relacionados com incubadoras, já que elas compartilham com as aceleradoras o fato de serem organizações que oferecem recursos e suporte para o desenvolvimento de startups, inclusive acesso a especialistas de diversas áreas (Peters, Rice e Sundararajan, 2004). Assim, na literatura de internacionalização existem estudos sobre programas de internacionalização de incubadoras de base tecnológica (Engelman; Fracasso, 2013), sobre redes como fator relevante no processo de internacionalização de incubadas (Engelman e Fracasso, 2013; Engelman, Zen e Fracasso, 2015) e sobre o uso de redes sociais por firmas incubadas (Lagemann e Loiola, 2013), mas a literatura é ainda incipiente sobre a internacionalização de firmas incubadas por meio de redes (Styles e Genua, 2008). Ou seja, existe uma lacuna na literatura concernente a estudos os quais iluminem o papel das redes e sua contribuição em termos de recursos no processo de internacionalização de empresas nascentes inovadoras assistidas por entidades de apoio ao crescimento das startups tais como incubadoras e aceleradoras.
O objetivo desta pesquisa foi identificar como uma aceleradora facilitaria e agilizaria a internacionalização de uma startup por meio da interação dentro de relacionamentos em rede social. Adicionalmente, buscou-se identificar quais os recursos adicionais que a aceleradora traria a internacionalização. Para atingir este objetivo, foi realizada uma pesquisa empírica de caráter exploratório por meio de estudo de caso único. Esta pesquisa permitiu a descrição e caracterização de um processo de internacionalização rápida de uma startup apoiada por uma aceleradora. Dentre seus resultados identificou-se que a rede social dos empreendedores foi substituída pela rede formal e estruturada da própria aceleradora, a qual por sua vez atuou como um intermediário na obtenção de informação e de recursos adicionais e impulsionou a internacionalização rápida da startup.

Este trabalho contribui assim para compreender e esclarecer o papel das redes sociais no processo de internacionalização de uma empresa nascente inovadora com restrições de recursos físicos, tecnológicos e financeiros. Além disso, acrescenta mais pesquisas empíricas ao ainda incipiente conjunto de estudos de campo relacionado à efetivação e teorias de rede na literatura brasileira sobre internacionalização (Matta e Mello, 2014).

Este trabalho está dividido em mais cinco partes, além desta introdução. Na próxima seção é feita a revisão da literatura, especialmente a de empreendedorismo internacional, teoria de redes sociais e efetivação. É então discutido de modo breve o método de pesquisa. Depois é apresentado o estudo de caso, e em seguida a sua discussão. A última seção sintetiza a contribuição deste estudo e propõe sugestões de pesquisas futuras.

\section{Referencial teórico}

Aceleradoras são um fenômeno bastante recente, posto que as primeira aceleradoras foram fundadas nos EUA em 2005 (Y Combinators) e 2007 (TechStars) (Cohen e Hochberg, 2014). Aceleradoras são compostas por executivos de negócios experientes os quais oferecem espaço de escritório, mentoria, networking, serviços administrativos, conhecimento e expertise para startups à medida que surge a necessidade para ajudá-las a vencer os primeiros estapas de sua criação (Hoffman e Kelley, 2012). 
Os conceitos de aceleradora e incubadora ainda não estão claramente distinguidos, e mesmo os praticantes confundem os termos (Cohen e Hochberg, 2014). Isto ocorre porque a aceleradora pode ser considerada um tipo de incubadora, já que compartilha com esta o fato de serem organizações que oferecem recursos e suporte para o desenvolvimento de startups, inclusive acesso a especialistas de diversas áreas (Peters, Rice e Sundararajan, 2004). Porém, as aceleradoras se diferenciam da conformação mais tradicional das incubadoras de universidade, por exemplo, por quase sempre investir na própria startup (muito frequentemente em troca de uma participação acionária), por se envolver mais no crescimento das empresas e também por ter um período menor de incubação (Hoffman e Kelley, 2012). Assim, a aceleradora se caracteriza por ser muito mais dinâmica, e pode ser definida pelo fato de seus programas de apoio ao crescimento serem a prazo fixo (curto), serem baseados em um grupo de empresas sendo acelerado ao mesmo tempo, incluir mentoria e elementos educacionais, e terminar em um evento público de apresentação das empresas (Cohen e Hochberg, 2014). As aceleradoras possuem algumas características operacionais distintas: espaço de trabalho integrado (coworking) no qual as empresas interagem em um só ambiente; período de incubação em geral de apenas três a cinco meses; apresentação para novos investidores ao final do programa; e acesso a apoio legal e mercadológico mesmo após o período de aceleração (Hoffman e Kelley, 2012). Há diversos tipos de apoio oferecido, principalmente recursos nas áreas jurídicas, administrativas e mercadológicas, interação em redes com mentores, ex-participantes e apresentação a novos investidores potenciais (Hoffman e Kelley, 2012). Na prática, os programas das aceleradoras são uma combinação de serviços ou recursos previamente separados que eram caros para um empreendedor nascente encontrar e obter (Hochberg, 2015). Além disso, alguns programas de primeira linha enfatizam o valor das redes de mentores e investidores que eles disponibilizam para as startups participantes (Hochberg, 2015).

No entanto, o fenômeno das aceleradoras ainda é recente e poucas startups já se graduaram e por isto existem poucos estudos, sobretudo empíricos, sobre o desempenho de aceleradoras e aceleradas (Cohen e Hochberg, 2014). Por esta razão, a revisão de literatura se baseou em estudos relacionados com incubadoras, os quais também são incipientes.

$\mathrm{Na}$ literatura sobre internacionalização de empresas incubadas no Brasil existem estudos sobre internacionalização de empresas incubadas ou graduadas (Baêta, Borges e Tremblay, 2006; Ramos e Alperstedt, 2010; Engelman e Fracasso, 2013; Fiates et al., 2013; Engelman, Zen e Fracasso, 2015). Por exemplo, Ramos e Alperstedt (2010) estudaram o caso de uma empresa de software incubada que somente fez uso de suas redes na expansão de sua internacionalização. Fiates et al. (2013) identificaram que a incubadora favorece a formação de redes de relacionamento que estimulam a inovação e a interação com atores que possibilitam a internacionalização. Outras pesquisas no Brasil abordam programas de internacionalização de incubadoras de base tecnológica (Baêta, Borges e Tremblay, 2006; Engelman e Fracasso, 2013) e redes como fator relevante no processo de internacionalização de incubadas (Engelman e Fracasso, 2013; Engelman, Zen e Fracasso, 2015). No entanto, a literatura é ainda incipiente sobre a internacionalização de firmas incubadas por meio de redes (Engelman e Fracasso, 2013), deficiência também apontada na literatura internacional (Styles e Genua, 2008).

As teorias de internacionalização de viés comportamental se baseiam nas percepções, atitudes e comportamentos dos tomadores de decisão, os quais buscam a redução de risco associado às decisões sobre onde e como expandir (Carneiro e Dib, 2007). As duas teorias mais representativas são Modelo de Uppsala (Johanson e Vahlne, 1977, 2009) e o Empreendedorismo Internacional (Oviatt e Mcdougall, 1994). A primeira teoria se baseia no aumento incremental de comprometimento da firma em mercados internacionais com a entrada nestes mercados vista como um posicionamento em redes internacionais (Johanson e Vahlne, 2009) ou também como um ato empreendedor (Schweizer, Vahlne e Johanson, 2010). Já o Empreendedorismo Internacional se dedica principalmente ao fenômeno das firmas de internacionalização rápida ou acelerada, as international new ventures ou born globals (Oviatt e Mcdougall, 1994). Nesta perspectiva, a definição de empreendedorismo internacional "é a descoberta, execução (enactment), avaliação e exploração de oportunidades - além das fronteiras nacionais - para criar produtos e serviços futuros" (Oviatt e 
Mcdougall, 2005, p. 540). No modelo de velocidade de internacionalização, esta última é um processo cuja velocidade é influenciada por quatro tipos de forças: a capacitadora: tecnologia; a motivadora: concorrência; a mediadora: percepção do empreendedor; e as moderadoras: rede e conhecimento. Dentre estas forças, a rede se destaca por influenciar o modo de entrada e os modos de operação em mercados internacionais (Oviatt e Mcdougall, 2005).

Além disso, a rede de relacionamentos foi reconhecida já há algum tempo como um importante elemento para o processo de internacionalização de empresas de pequeno e médio porte, tanto na área de Negócios Internacionais (Welch e Welch, 1996; Madsen e Servais, 1997; Tikkanen, 1998) quanto na área de Empreendedorismo Internacional (Oviatt e Mcdougall, 1994; Sharma e Blomstermo, 2003). Empiricamente foram identificadas diversas funções de rede, especificamente o uso de recursos de terceiros (Coviello e Cox, 2006), a obtenção de conhecimento sobre mercados internacionais (Bell, Mcnaughton, Young e Crick, 2003) e escolha do modo de entrada e do mercado externo (Coviello e Munro, 1995; 1997). Ademais, vários estudos empíricos que buscam entender a a importância da rede social no processo de internacionalização (Ellis, 2011), e mais especificamente, a importância dos laços fracos (Ellis, 2011; Nowiński e Rialp, 2015) e a superação de buracos estruturais em mercados internacionais (Chandra, Styles e Wilkinson, 2009).

Redes sociais são um conceito fundamental para - Emprendedorismo Internacional porque o empreendedorismo pode ser entendido como uma atividade de formação de redes (networking) (Dubini e Aldrich, 1991). Ou seja, o empreendedorismo está inserido em uma rede de relações sociais contínuas, e ele se realiza por ligações conectando os empreendedores a recursos e oportunidades existentes na rede (Aldrich e Zimmer, 1986). A rede social pode ser entendida como o conjunto de pessoas composto de um indivíduo e de sua família, seus amigos próximos e seus conhecidos (Granovetter, 1983), dentro da qual relacionamentos são criados e mantidos (Burt, 1992). A força de um relacionamento tem duas dimensões independentes, contatos frequentes e proximidade emocional (Burt, 1992), e sua força também depende do nível, frequência e reciprocidade dos relacionamentos entre as pessoas (Aldrich e Zimmer, 1986). A força do laço é importante para se caracterizar o processo de transmissão de informações em uma rede e "a força de um laço é uma combinação da quantidade de tempo, da intensidade emocional da intimidade e dos serviços recíprocos que caracterizam o vínculo" (Granovetter, 1973, p. 1361). Relacionamentos baseados em laços fracos têm duração curta e menor frequência de contato e exemplos seriam os relacionamentos amigáveis mas estritamente de negócios (Aldrich, 1999). Os laços fracos são mais numerosos por não requererem muito investimento e podem ser fontes cruciais de informação e knowhow (Oviatt e Mcdougall, 2005). Ordinariamente, são os laços fracos os que se conectam com os intermediários e que permitem o relacionamento com novas redes e portanto com novas fontes de informação (Burt, 1997) e assim permitem a superação de buracos estruturais (Burt, 1992). Os buracos estruturais são lacunas entre redes distintas e funcionam como pontes para novas informações por meio de intermediários que se posicionam nestes buracos (Burt, 1992). O intermediário que atua nos buracos estruturais controla o fluxo de informação em três dimensões: acesso, timing e referência (Burt, 1997). O acesso está relacionado com qual informação está disponível; o timing diz respeito à adequação do momento o qual a informação é disponibilizada; e a referência está relacionada com a fidedignidade da informação (Burt, 1997).

Também a teoria de efetivação pode ser incorporada na pesquisa de Empreendedorismo Internacional contribuindo para o entendimento do papel das redes no processo de internacionalização (Sarasvathy; et al., 2014). Isto porque esta teoria leva em consideração a rede social do empreendedor tanto em termos dos meios atuais à sua disposição quanto a incorporação de stakeholders que trazem recursos adicionais (Sarasvathy, 2008). A lógica efetiva é uma heurística cognitiva que descreve como empreendedores utilizam recursos sob seu controle na constituição de novos negócios e é particularmente útil em situações de grande incerteza, tais como a criação de startups. A efetivação se baseia em cinco princípios de ação do empreendedor: decisão baseada em meios já disponíveis - e não em metas a serem atingidas; identificação e administração do nível de perda suportável; criação de parcerias para a obtenção de recursos ainda não disponíveis; transformação das contingências em oportunidade; e, por fim, cocriação das condições futuras pela interação dos outros agentes - ao invés do uso de técnicas que 
tentam prever o futuro. Estes princípios podem ser nomeados e detalhados da seguinte maneira (Sarasvathy, 2008):

Pássaro na mão: o empreendedor se concentra nos meios já disponíveis para aproveitar as oportunidades. Assim, ele se detém nas suas características pessoais (quem sou eu?), no seu conhecimento (o que eu sei?) e em suas redes (quem eu conheço?);

Perda suportável: ao invés de estimar o retorno do investimento e o custo de oportunidade de realizá-lo, o empreendedor se baseia no valor que ele está disposto a perder caso o empreendimento não seja bem sucedido;

Colcha de retalhos: as parcerias são o principal mecanismo para a obtenção de recursos adicionais. Estas parcerias são criadas com stakeholders que acreditam no negócio;

Limonada: este princípio entende que uma lógica efetiva pode ser melhor para explorar situações imprevistas que ocorrem fortuitamente; assim, as surpresas podem ser "alavancadas" ao invés de evitadas ou adaptadas;

Piloto automático: os empreendedores não tentam prever o futuro por causa das grandes incertezas associadas a ele; ao invés disso, eles procuram controlá-lo criando as próprias oportunidades na interação com os outros agentes.

Há algumas características do processo de internacionalização que podem ser frutiferamente analisadas e estudadas por meio da efetivação, como por exemplo incerteza em mercados externos, recursos limitados e dinâmica de redes. Esta última está contida nos princípios de 'pássaro na mão' ("quem eu conheço?") e de 'colcha de retalhos'. O último princípio representa o desenvolvimento e o estreitamento de laços de redes para acelerar o desenvolvimento do projeto do empreendedor. No âmbito do empreendedorismo internacional, não é necessariamente a rede que faz a diferença, mas sim o modo como o empreendedor a utiliza (Sarasvathy et al., 2014). A teoria de efetivação também pode ser útil para o entendimento de processos de internacionalização não planejados (Chandra, Styles e Wilkinson, 2009; Kalinic; Sarasvathy e Forza, 2014).

\section{Método de pesquisa}

A questão de pesquisa procurou entender como a aceleradora facilitou e agilizou a internacionalização de uma startup por meio de seu papel de integração dos diversos relacionamentos de rede. O estudo de caso foi escolhido como método de pesquisa porque se buscou realizar uma pesquisa exploratória de um fenômeno contemporâneo inserido em um contexto complexo, além de estar baseada em uma questão do tipo "como" (Yin, 2001). Foi identificada uma startup brasileira de base tecnológica com um modelo de negócios considerado único em todo o mundo, a Queremos!. O objetivo desta pesquisa foi o estudo de um tipo muito específico de empresa, ou seja, uma startup de conteúdo tecnológico pertencente à indústria criativa com um modelo de negócios único no mundo e que se internacionalizou por meio de uma aceleradora. Portanto, o estudo de múltiplos casos se torna menos importante, e o estudo de caso único se justifica pois o enfoque principal é o conhecimento aprofundado do contexto de uma firma (Siggelkow, 2007), o que é sugerido também para estudos de efetivação na internacionalização de born globals (Andersson, 2011). Os procedimentos de pesquisa seguiram o preconizado por Yin (2001) e como a pesquisa buscou valorizar a perspectiva de quem efetivamente vivenciou o processo de internacionalização, a coleta de dados primários foi a entrevista semi-aberta em profundidade (Miles \& Huberman, 1994).

Foram realizadas uma entrevista com um dos sócios (e diretor de operações da empresa) e outra entrevista com um dos executivos da aceleradora. Ambas entrevistas foram feitas com dois pesquisadores, para dirimir eventuais vieses dos entrevistadores. As entrevistas foram gravadas e posteriormente transcritas e analisadas para identificação de categorias e principais eventos na história da empresa e no seu processo de internacionalização. A escolha de apenas um entrevistado na empresa é compatível com a proposição de que o empreendedor é a melhor fonte de dados primários, pois ele é o mais bem informado sobre a firma (Evangelista, 2005). A análise de conteúdo foi feita de acordo com as etapas de préanálise, exploração do material e tratamento dos resultados (Bardin, 1996). A primeira etapa da pesquisa foi a sistematização do corpus de análise. Nesta etapa foi feita primeiramente a coleta de dados secundários em websites e páginas de Facebook da startup e da aceleradora, páginas de revistas especializadas e videos de eventos dos quais a 
empresa participou. Especificamente, as fontes incluíram websites da empresa QUEREMOS! e WE DEMAND, da aceleradora 21212, do evento Tech Crunch Disrupt, além das páginas da empresa e da aceleradora no Facebook, no Twitter e também revistas digitais que as abordaram, como Le Monde, Contagious, Future of Entertainment, TEDxRio, Music Canadian Week, dentre outras. Estas fontes adicionais permitiram a triangulação de dados com as entrevistas e portanto aumentou a validade da pesquisa (Yin, 2001).

Posteriormente foram realizadas e transcritas as entrevistas. Na segunda estapa foi feita a exploração do material, na qual se realizou a sistematização das categorias baseadas no referencial teórico. Finalmente na terceira etapa foi feito o tratamento do material, com inferência e interpretação das categorias, visando identificar conexões e compreender o fenômeno às luz da literatura. Como a empresa ainda era muito nova, mesmo com as múltiplas fontes de informação disponíveis, acreditou-se que a coleta de dados secundários tenha alcançado o ponto de exaustão. Os resultados foram organizados levando-se em consideração os conceitos identificados na revisão de literatura, e as categorias buscadas estavam relacionadas com as etapas do processo de internacionalização, a importância dos relacionamentos neste processo e a função da aceleradora nas diversas etapas da internacionalização.

A utilização de um caso único se justificou pela especificidade da empresa (Siggelkow, 2007) em relação a diversas caracteríticas relacionadas ao seu modelo de negócio, à dinâmica do setor de aceleradoras e à indústria na qual ela está inserida. Primeiro por ser a Queremos! a única ganhadora brasileira no concorrido evento internacional Tech Crunch Disrupt e também pelo seu modelo de negócios único no mundo que poderia oferecer novas perspectivas na distribuição, nacional ou internacional, de bens e serviços da indústria criativa (Unctad, 2010).

O principal aspecto refere-se ao fato dela ter sido até 2014 a única startup brasileira a ter participado do mais importante momento do maior evento de inovação e empreendedorismo digital do mundo, o Tech Crunch Disrupt, o qual está localizado perto do Vale do Silício e circundado por grandes empresas de venture capital. Em mercados de alta tecnologia, onde as taxas de mortalidade de startups são elevadas devido a grandes mudanças tecnológicas em curto espaço de tempo, participar do maior evento da área significa adquirir fôlego para sobreviver por um tempo mais prolongado. Além disso, o modelo de negócio único da empresa poderia ter desdobramentos na maneira como são distribuídos bens e serviços da indústria criativa. A maioria dos canais de distribuição para produtos criativos são dominados por grandes multinacionais, mas o advento da digitalização e da internet ocasionaram grandes mudanças na distribuição (Unctad, 2010). A QUEREMOS! poderia ser parte de uma mudanca radical na maneira como a indústria musical está estruturada, pois cada vez mais artistas estão se dedicando a apresentações ao vivo como a sua principal fonte de renda, e distribuindo gratuitamente as suas músicas gravadas (Unctad, 2010). E a Queremos! justamente permite o contato direto dos artistas com seu público e a identificação de lugares para apresentações ao vivo. Exatamente por tal singularidade do evento (Yin, 2001), que se buscou privilegiar a compreensão dos fatores que geraram tal alavanca para rápida internacionalização, o que a distingue das outras startups.

\section{Descrição do caso: Internacionalização da QUEREMOS!}

A QUEREMOS! era uma plataforma que atuava no financiamento de espetáculos musicais por meio de uma ferramenta digital de financiamento coletivo baseada na internet. Fundada no Rio de Janeiro em 2010, a empresa promovia espetáculos musicais de artistas internacionais que não eram realizados devido à imprevisibilidade do público local. Os sócios já eram profissionais com mais de trinta anos e carreiras estabelecidas em áreas da indústria cultural como televisão, cinema e publicidade, dentre outras.

A plataforma tornou-se um canal de comunicação direta com uma base de usuários constantes visando o financiamento e promoção de eventos musicais. O modelo funcionava assim: interessados em um evento disponível na plataforma compravam ingressos antecipadamente; se o número mínimo de interessados não fosse atingido, o dinheiro era devolvido integralmente. Se o número mínimo fosse conseguido, a empresa negociava a vinda do artista; com o evento confirmado, os ingressos pré-vendidos eram distribuídos e mais ingressos eram vendidos para o público em geral. Em 2014 a empresa teve receita de US\$ 1,4 milhão em uma base de 400 mil 
usuários. Em quatro anos a empresa já havia realizado mais de 100 concertos com mais de um milhão de pedidos gerados e 158 mil ingressos vendidos. Baseado em um encontro fortuito entre um sócio da startup e outro da aceleradora, surgiu a oportunidade de participar de um processo de aceleração da 21212. O modelo da startup foi identificada pela aceleradora como único no mundo e foi a razão para o convite em participar em um processo de aceleração já iniciado. Além do suporte tradicionalmente oferecido por uma aceleradora, o elemento determinante para a aceitação do convite por parte da empresa foi o fato de que a 21212 permitiria uma internacionalização mais rápida do que seria possível somente com o uso dos relacionamentos dos sócios. De acordo com o depoimento do diretor:

"a aceleradora apontou que $2 \%$ do mercado norteamericano ia ser muito mais do que $80 \%$ do mercado brasileiro, e como o modelo precisava escalar muito para fazer sucesso, sabíamos que tinha que ser algo grande, que escalasse rápido."

A estruturação jurídica da empresa com vistas à captação de investidores estrangeiros também foi muito importante. A aceleradora se tornou sócia da empresa, e com isso houve interesse na continuidade do desenvolvimento da empresa mesmo após o fim do período de aceleração. Para apoiar o desenvolvimento da startup, a aceleradora buscou em sua própria rede mentores especializados em tecnologia e associados à indústria do entretenimento. Segundo o diretor da Queremos:

"Acelerou tudo, o processo de criação, a estruturação do negócio (mentoring, coaching)... no nosso caso, trouxemos os nossos mentores especialistas da área musical, e ao mesmo tempo usávamos a rede da aceleradora."

A aceleradora também impulsionou a internacionalização da firma por meio da sua inclusão no evento e a preparação da apresentação no Tech Crunch Disrupt 2012, no qual startups com modelos de inovação radical fizeram apresentações a potenciais investidores internacionais. Neste ano, a empresa fez parte das doze selecionadas dentre cinco mil inscritas do mundo inteiro. Na ocasião, além de ter sido premiada, a empresa obteve um investidor; e após o evento a aceleradora ainda apresentou a empresa a mais firmas de venture capital da região.
O evento foi considerado a porta de entrada da empresa para o mercado internacional, já que a visibilidade alcançada no evento proporcionou tanto novos investidores quanto divulgação gratuita do modelo de negócios. Os novos investimentos foram usados explicitamente para a internacionalização da empresa. $\mathrm{Na}$ entrada da empresa no mercado americano percebeu-se rapidamente que havia significativas diferenças em relação ao mercado musical brasileiro e a plataforma teve de ser adaptada para levar em conta muito mais tipos de participantes de mercado do que os existentes no Brasil. A operacionalização da entrada no mercado americano foi realizada com a realocação de dois sócios para facilitar o processo de adaptação ao mercado. Foram criados dois novos escritórios: um em Nova lorque, pela proximidade geográfica com o Brasil e pelo fato de aceleradora possuir seu escritório americano na cidade, com o objetivo de cuidar do relacionamento com atuais e potenciais investidores; e outro em Los Angeles, considerada a "capital mundial" da indústria de entretenimento, com o objetivo de estreitar as relações com artistas e músicos.

Dada a complexidade do novo mercado houve, portanto, a necessidade de criar um novo modelo adaptado às diferentes características do mercado local. Assim foi desenvolvido um novo formato no qual havia uma maior ênfase no relacionamento do artista com sua base de fãs. Assim, os dados agregados dos usuários permitia aos artistas o uso de uma ferramenta para desenvolver estratégias mercadológicas por meio de inteligência de mercado (business intelligence). Em troca desta ferramenta gratuita, a plataforma cobrava uma taxa de todas as transações realizadas no seu ambiente. Para garantir a divulgação da plataforma e a ampliação da base de usuários, foi realizada uma parceria com o Twitter, na qual as informações geradas pelos próprios usuários eram transformadas em pedidos diretos para as duas plataformas, a brasileira e a internacional. Apesar do modelo ter sido criado levando em conta as especificidades do mercado americano, a plataforma passou a atrair fãs de outros países. No segundo semestre de 2014, europeus começaram a utilizar a plataforma e, consequentemente, a demandar concertos em alguns países do continente. Com isso, a internacionalização da plataforma iria além do mercado americano, um processo motivado inteiramente pela demanda espontânea de sua base de usuários. 


\section{Análise do caso}

A análise do caso está dividida em duas partes: a substituição da rede social dos sócios pela aceleradora, inclusive no processo de internacionalização da firma; e a adaptação do modelo de negócios para o mercado internacional. O princípio da "colcha de retalhos" da lógica efetiva encara o estabelecimento de parcerias como mecanismo fundamental para obter os recursos necessários para a viabilização da empresa (Sarasvathy, 2008). Este princípio da "colcha de retalhos" serve para ilustrar a substituição da rede social informal da firma pela rede social formal estruturada representada pela aceleradoras, posto que o processo de internacionalização foi financiado por novos investidores contatados por meio da aceleradora. Desta maneira, fica claro que a aceleradora atuou como força moderadora da velocidade de internacionalização da firma, ou seja, ela aumentou a rapidez da entrada da firma em novos mercados internacionais (Oviatt e Mcdougall, 2005). A mais importante característica da rede é o uso de buracos estruturais para a obtenção de informações de outras redes além da rede da firma. Neste caso a aceleradora atuou como uma intermediária e controla os fluxos de informação nas três dimensões de acesso, timing e referência (Burt, 1997). Estas três dimensões definem o que, quando e quem tem acesso à firma, e estas condições foram controladas pela aceleradora. Esta já havia constituído uma extensa rede composta de mentores e investidores potenciais que poderiam contribuir para o desenvolvimento da firma, sendo que a seleção de investidores e mentores era feita em função das características e necessidades da firma. No processo de internacionalização este papel ficou evidente quando a aceleradora organizou encontros com investidores, definiu a configuração jurídica para a internacionalização e apoiou a abertura dos escritórios americanos da firma.

$\mathrm{Na}$ terceira etapa, a firma soube mudar rapidamente o modelo de negócio diante da realidade norte-americana; e criou um novo nome para o website internacional (WE DEMAND!) a fim de aumentar a visibilidade da marca nos Estados Unidos. A percepção quanto à necessidade da mudança do modelo de negócio foi devida à constatação da maior sofisticação e complexidade deste mercado. Eles adaptaram o modelo da plataforma para reaproveitar o recurso de uma grande base de usuários para oferecer novos serviços a um novo cliente, o artista.
Isto explicita o princípio de lógica efetiva da "limonada" (Sarasvathy, 2008), no qual se deve reconhecer a importância do inesperado para criar novas oportunidades. Além disso, eles adaptaram a plataforma à maior complexidade da indústria musical americana e abriram um escritório na capital mundial do entretenimento para acompanhar de perto as novas tendências e aprofundar o relacionamento com este importante agente da sua plataforma. Desta forma, eles buscaram controlar o futuro da firma em um novo mercado com alto nível de incerteza por meio da criação das suas próprias oportunidades na interação com outros agentes, o que constituiria o princípio do "piloto automático" (Sarasvathy et al., 2014). É importante observar que a empresa não seguiu a "cadeia de estabelecimento" descrita no modelo de Uppsala tradicional (Johanson e Vahlne, 1977) e pularam as duas primeiras etapas de exportações irregulares e de agente local para já instalar escritórios no mercado hospedeiro. Além disso, eles não se internacionalizaram para se posicionar em uma rede de negócios internacional, mas sim como um ato empreendedor (Schweizer, Vahlne e Johanson, 2010).

Outro ponto relevante é o fato de que o modelo de negócios foi desenvolvido para as características do mercado americano mas se iniciou uma expansão motivada espontaneamente pela demanda de uma base de usuários localizada na Europa. Este modo de entrada em novos mercados revelou que a expansão para novos mercados foi imprevista e não planejada, reforçando o argumento de que muitas vezes a internacionalização é contingencial e inesperada (Sarasvathy et al., 2014). A Tabela 1 resume os achados da pesquisa e os relaciona com a literatura.

\section{Considerações finais}

A pesquisa apresentada neste artigo teve como objetivo explorar, por meio de estudo de caso único, o papel das redes no processo de internacionalização rápida de uma startup de base tecnológica participante de um programa de uma aceleradora brasileira. Foram identificadas as dimensões pelas quais uma aceleradora atuou não como mediadora do acesso a rede de negócios (Mcadam e Marlow, 2007) ou do fortalecimento da rede do empreendedor (Engelman \& Fracasso, 2013), mas sim no papel de substituta da rede social no processo de internacionalização. Isto ocorreu porque a aceleradora cumpriu várias funções da rede social do 
Tab. 1

Comparativo dos achados na pesquisa com conceitos da literatura

\begin{tabular}{|c|c|}
\hline Achados da Pesquisa & Conceitos Relacionados \\
\hline $\begin{array}{l}\text { Aceleradora substituiu a rede social da empresa e } \\
\text { aumentou a sua velocidade de internacionalização }\end{array}$ & $\begin{array}{l}\text { Redes influenciam positivamente a velocidade de } \\
\text { internacionalização (Oviatt e Mcdougall, 2005) }\end{array}$ \\
\hline $\begin{array}{l}\text { Aceleradora influenciou modo de entrada e seleção } \\
\text { do mercados externo, fornecendo informações } \\
\text { sobre o mercado e a indústria musical americana }\end{array}$ & $\begin{array}{l}\text { Redes influenciam modo de entrada e escolha do mercado } \\
\text { externo (Coviello e Munro, 1995; 1997); e permitem } \\
\text { aquisição de conhecimento sobre mercados externos (Bell et } \\
\text { al., 2003) }\end{array}$ \\
\hline $\begin{array}{l}\text { Mentores da indústria do entretenimento e } \\
\text { investidores recém-contatados permitiram o fluxo } \\
\text { de informação e contato com novos parceiros no } \\
\text { mercado americano }\end{array}$ & $\begin{array}{l}\text { Laços fracos (Granovetter, 1973) constituídos no processo de } \\
\text { internacionalização (Ellis, 2011) atuam como intermediários } \\
\text { que superam buracos estruturais entre redes distintas (Burt, } \\
\text { 1992) em mercados internacionais (Chandra, Styles e } \\
\text { Wilkinson, 2009) }\end{array}$ \\
\hline $\begin{array}{l}\text { Aceleradora controlou o fluxo de informação } \\
\text { definindo qual informação, quando e com que } \\
\text { qualidade foi fornecida à startup no seu processo } \\
\text { de internacionalização }\end{array}$ & $\begin{array}{l}\text { São identificadas as três dimensões do controle de } \\
\text { informação pelo intermediário informação em rede: acesso, } \\
\text { timing e referência (Burt, 1997) }\end{array}$ \\
\hline $\begin{array}{l}\text { Aceleradora apoiou o crescimento da firma com } \\
\text { recursos financeiros, jurídicos e mercadológicos; } \\
\text { investidores americanos trouxeram novos recursos } \\
\text { financeiros }\end{array}$ & $\begin{array}{l}\text { São incorporados stakeholders os quais acrescentam recursos } \\
\text { adicionais (Sarasvathy et al., 2014); rede permite a obtenção } \\
\text { recursos de terceiros (Coviello e Cox, 2006) }\end{array}$ \\
\hline $\begin{array}{l}\text { A firma adaptou a plataforma à maior } \\
\text { complexidade da indústria musical americana }\end{array}$ & $\begin{array}{l}\text { Aproveitamento das situações imprevistas: princípio da } \\
\text { "limonada" (Sarasvathy et al., 2014) }\end{array}$ \\
\hline $\begin{array}{l}\text { Criação de novos serviços específicos para o } \\
\text { mercado americano com a incorporação na } \\
\text { plataforma de novos agentes }\end{array}$ & $\begin{array}{l}\text { Controlar o futuro em ambiente de alto nível de incerteza } \\
\text { por meio da interação com outros agentes: princípio do } \\
\text { "piloto automático" (Sarasvathy et al., 2014). }\end{array}$ \\
\hline $\begin{array}{l}\text { Entrada não planejada no mercado europeu } \\
\text { baseada em pedidos espontâneos de fãs }\end{array}$ & $\begin{array}{l}\text { Entrada em mercados externos pode ser baseada em } \\
\text { acontecimentos fortuitos: criação de oportunidades é não } \\
\text { planejada (Chandra, Styles e Wilkinson, 2009; Kalinic, } \\
\text { Sarasvathy e Forza, 2014; Sarasvathy et al., 2014,). }\end{array}$ \\
\hline
\end{tabular}

Fonte: Elaborado pelos Autores

empreendedor, tais como: a intermediação do fluxo de informação que permitiu a identificação de novas oportunidades (Burt, 1992) por meio de sua rede de mentores e contatos internacionais (Hochberg, 2015); e a oferta de recursos físicos, humanos, financeiros e organizacionais (Coviello e Cox, 2006) no processo de aceleração (Cohen e Hochberg, 2014; Hoffman e Kelley, 2014). Ainda na sua função de rede, a aceleradora atuou como um mecanismo que influenciou positivamente a velocidade de internacionalização da empresa (Oviatt e Mcdougall, 2005), permitindo o ingresso mais rápido da empresa no mercado americano. Além disso, os achados reforçaram a utilidade da aplicação da teoria de efetivação no estudos de redes na internacionalização, especialmente a incorporação de stakeholders (e os seus recursos adicionais), o aproveitamento de contingências e a criação de oportunidades internacionais pela interação entre agentes (Sarasvathy; et al., 2014). É possível que este papel de "substituta" da rede seja mais provável de ocorrer em aceleradoras, posto que estas têm um maior comprometimento de recursos financeiros do que as incubadoras tradicionais.

Em termos empíricos, este estudo contribuiu para um maior entendimento do papel das aceleradoras no processo de internacionalização de startups brasileiras, ao mostrar que a aceleradora pode ser eficaz não apenas no crescimento e continuidade de uma empresa nascente, mas também na sua internacionalização, o que agrega mais uma pesquisa empírica aos ainda escassos estudos de eficácia de aceleradoras (Cohen e Hochberg, 2014). Os achados indicaram também como a aceleradora pôde agir como um substituto formal e estruturado da rede 
social informal dos empreendedores de uma empresa nascente, o que é compatível com estudos que apontam que incubadoras permitem o fortalecimento e expansão das redes de negócios das incubadas (Engelman e Fracasso, 2013). Em termos teóricos, a contribuição deste estudo foi o de iluminar os mecanismos pelos quais uma pequena empresa obtém recursos adicionais (Coviello e Cox, 2006) como conhecimento e capital para o seu processo de internacionalização com a incorporação de novos stakeholders (Sarasvathy et al., 2014) e também como ela expande a sua rede por meio de seus relacionamentos de rede atual (Sarasvathy et al., 2014). As contribuições práticas ou gerenciais desta pesquisa apontam que, para garantir a eficácia da internacionalização das startups, os gestores de aceleradoras e incubadoras devem buscar constituir uma rede de mentores e especialistas com projeção internacional para atuar como intermediários entre a startup e eventuais parceiros internacionais como investidores, advogados e outros.

Esta pesquisa apresenta a limitação de ser um estudo de caso único e, portanto, os seus achados não podem ser generalizados para outras firmas ou setores. Como sugestão de pesquisas futuras, podem ser investigados novos tipos de configuração de incubadoras e aceleradoras com ou sem programas definidos de internacionalização, bem como as características diferenciais das aceleradoras independentes. Além disso, pode-se investigar o fenômeno cada vez mais importante das aceleradoras "corporativas". Também há espaço para novos estudos exploratórios em outros setores de alta tecnologia e com inserção internacional como software, por exemplo. Estudos empregando métodos quantitativos poderiam comparar a velocidade de internacionalização de startups de alto e baixo conteúdo tecnológico ou aceleradoras e incubadoras, com ou sem fins lucrativos. Finalmente, estudar melhor o papel de incubadoras ou aceleradoras no processo de identificação de oportunidades empreendedoras internacionais parece ser um próximo passo nos estudos sobre o tema.

\section{Referências}

- Aguilhar, L. (2014) Aceleradoras de startups ganham força no Brasil, mas precisam provar eficiência. Estadão, Disponível em: <http://blogs.estadao.com.br/link/aceleradoras/> Acesso em: 4 out. 2014.
- APEX-BRASIL. (2015) Disponível em: <http://www.apexbrasil.com.br/Home/Index>.

Acesso em: 22 fev. 2015.

- BELL, J. et al. (2003) Towards an integrative model of small firm internationalisation. Journal of International Entrepreneurship, 1 (4), p. 339-362. DOI: 10.1023/A:1025629424041

- BURT, R. S. (1992) Structural holes: the social structure of competition. Cambridge, MA: Harvard University Press.

- BURT, R. S. (1997) The contingent value of social capital. Administrative Science Quarterly, 42 (2), p. 339-365. DOI: $10.2307 / 2393923$

- CARNEIRO, J.; DIB, L. (2007) Avaliação comparativa do escopo descritivo e explanatório dos principais modelos de internacionalização de empresas. INTERNEXT - Revista Eletrônica de Negócios Internacionais da ESPM, 2 (1), p. 1-25.

- COVIELlO, N. E.; COX, M. P. (2006) The resource dynamics of international new venture networks. Journal of International Entrepreneurship, 4 (2/3), p. 113-132. DOI: 10.1007/s10843-007-0004-4

- DORNELAS, J. (2014) Empreendedorismo: transformando ideias em negócios. Rio de Janeiro: Empreende / LTC.

- ENGELMAN, R.; FRACASSO, E. M. (2013) Contribuição das incubadoras tecnológicas na internacionalização das empresas incubadas. Revista de Administração, 48 (1), p. 165-178. DOI: 10.5700/rausp1080

- $\quad$ ENGELMAN, R.; ZEN, A. C.; FRACASSO, E. M. (2015) The impact of the incubator on the internationalization of firms. Journal of Technology Management \& Innovation, 10 (1), p. 29-39. DOI: 10.4067/S0718-27242015000100003

- EVANGelista, F. (2005) Qualitative insights into the international new venture creation process. Journal of International Entrepreneurship, 3 (3), p. 179-198. DOI: 10.1007/s10843-005-4204-5

- GRANOVETTER, M. (1973) The strength of weak ties. American Journal of Sociology, 78 (6), p. 13601380.

- HOFFMAN, D. L.; KELLEY, N. R. (2012) Analysis of accelerator companies: an exploratory case study of their programs, processes, and early results. Small Business Institute Journal, 8 (2), p. 54-70.

- jOHANSON, J.; MATTSSON, L.-G. (1988) Internationalization in industrial systems: a network approach. In: HOOD, N.; VAHLNE, J. (Ed.). Strategies in global competition. New York: Croom Helm, p. 287-314. 
- JOHANSON, J.; VAHLNE, J.-E. The internationalization process of the firm: a model of knowledge development and increasing foreign market commitments. Journal of International Business Studies, v. 8, n. 1, p. 25-34, 1977. doi:10.1057/palgrave.jibs.8490676

- JONES, M. V.; COVIELLO, N.; TANG, Y. K. (2011) International entrepreneurship research (19892009): a domain ontology and thematic analysis. Journal of Business Venturing, 26 (6), p. 632-659. DOI:10.1016/j.jbusvent.2011.04.001

- LAgemanN, G. V.; LOIOLA, E. (2013) Redes sociais informais e desempenho de empresas incubadas. Revista de Ciências da Administração, 1 (1), p. 22-36. DOI: 10.5007/21758077.2013v15n37p22

- MiCROSOFT VENTURES. (2014) Accelerators. Disponível em: <https://www.microsoftventures.com/accelerator s>. Acesso em: 20 out. 2014.

- MAtTA, J. R. N.; MEllo, R. D. C. (2014) A internacionalização de uma empresa brasileira de software de segurança à luz das teorias de redes e effectuation, InternexT - Revista Eletrônica de Negócios Internacionais da ESPM, 9 (3), p. 78-94.

- MCADAM, M.; MARLOW, S. (2007) Building futures or stealing secrets? Entrepreneurial cooperation and conflict within business incubators. International Small Business Journal, 25 (4), p. 361 382. DOI: $10.1177 / 0266242607078563$
- MILES, M.; HUBERMAN, A. (1994) Qualitative data analysis: an expanded sourcebook. Thousand Oaks: Sage.

- OVIATT, B. M.; MCDOUGALL, P. (1994) Toward a theory of international new ventures. Journal of International Business Studies, 25 (1), p. 45-64. DOI:10.1057/palgrave.jibs.8490193

- OVIATT, B. M.; MCDOUGALL, P. (2005) Defining international entrepreneurship and modeling the speed of internationalization. Entrepreneurship Theory and Practice, 29 (5), p. 537-554. DOI: 10.1111/j.1540-6520.2005.00097.x

- SARASVATHY, S. D. (2008) Effectuation: Elements of entrepreneurial expertise. Cheltenham, UK: Edward Elgar.

- SARASVATHY, S. D. et al. (2014) An effectual approach to international entrepreneurship: overlaps, challenges, and provocative possibilities. Entrepreneurship Theory and Practice, 38 (1), p. 71-93. DOI: 10.1111/etap.12088

- StYles, C.; GenUA, T. (2008) The rapid internationalization of high technology firms created through the commercialization of academic research. Journal of World Business, 43 (2), p. 146-157. DOI:10.1016/j.jwb.2007.11.011

- YIN, R. K. (2001) Estudo de caso: planejamento e métodos. Porto Alegre: Bookman.

\section{Sobre os autores}

- Carolaine Fabricia Bonk Sarmento é Bacharel em Defesa e Gestão Estratégica Internacional pela Universidade Federal do Rio de Janeiro -UFRJ, Rio de Janeiro, RJ, Brasil.E-mail: carolbonk@gmail.com

- Carlos Augusto Septimio de Carvalho é Doutorando em Administração de Empresas pela Universidade Federal do Rio de Janeiro - COPPEAD/UFRJ, Rio de Janeiro, RJ, Brasil. E-mail: carlos.carvalho@coppead.ufrj.br

- Luis Antonio da Rocha Dib é Doutor em Administração pela Universidade Federal do Rio de Janeiro COPPEAD/UFRJ, Rio de Janeiro, RJ, Brasil. Também é Professor Adjunto no Programa de Pós-Graduação em Administração na mesma instituição.E-mail: dib@coppead.ufrj.br 


\title{
Effectuation and the influence of social networks on the internationalization of accelerated startups
}

Carolaine Fabricia Bonk Sarmento, Carlos Augusto Septimio de Carvalho and Luis Antonio da Rocha Dib

Federal University of Rio de Janeiro - UFRJ, Rio de Janeiro, RJ, Brazil.

\begin{tabular}{l}
\hline ARTICLE DETAILS \\
\hline Article history: \\
Received 29 June 2015 \\
Accepted 3 Februaryr 2016 \\
Available online in 30 April 2016 \\
Double Blind Review System \\
Scientific Editors \\
Eduardo Eugênio Spers \\
\hline Keywords: \\
International entrepreneurship \\
Social networks \\
Effectuation \\
Accelerators \\
Music industry \\
\end{tabular}

\begin{abstract}
Accelerators recently became a more active alternative to incubators as a mechanism for supporting and developing technology-based startups, especially in their internationalization. At the same time, social networks enable and increase the speed of the process of small firms' internationalization by allowing the attainment of third-party resources and market knowledge. The objective of this research was to better understand how accelerators speed up the process of internationalization for incubated startups. A single case study was conducted on an internet startup. Analysis of the company's internationalization process was based on the theoretical approach of international entrepreneurship and effectuation theory. The results indicated that the startup benefited from resources and knowledge obtained through accelerators that would usually be obtained through a social network. In addition to the accelerator, by replacing informal social networks with more formal and structured ones, the firm was able to increase the speed of internationalization. The main contribution of this article is to illuminate and detail the connection between the theoretical principles of effectuation and the use of social networks in the internationalization of small firms.
\end{abstract}

C 2016 Internext | ESPM. All rights reserved! 